\title{
Development of Wire Arc Additive Manufacturing setup
}

\author{
Sushrut M Kulkarni , Sachin A Mastud ${ }^{2}$ \\ ${ }^{1}$ PG student, ${ }^{2}$ Associate Professor \\ ${ }^{1,2}$ Department of Mechanical Engineering, Veermata Jijabai Technological Institute (VJTI), Mumbai, India
}

\begin{abstract}
Wire Arc Additive Technology (WAAM) is one of the lesser known metal additive manufacturing technology which holds the potential to fulfil the requirements of modern industry like sustainability, low cast and environment friendliness. This study focuses on the design and development of wire arc-based metal additive manufacturing setup for industrial purpose which include the integration of GTAW technique with specially designed Cartesian robot along with the use of CAD/CAM software for pre-processing, monitoring and control to manufacture a $3 D$ metallic component. As well as the process parameter selection for material ER309L for prescribed WAAM technology using the Taguchi's method has been discussed. Taguchi's optimization and $S / N$ data revels that the optimal welding parameter for EN309L material are 225 Amp current, $130 \mathrm{~mm} / \mathrm{min}$ travel speed and $1800 \mathrm{~mm} / \mathrm{min}$ wire feed speed and it has been found that the wire feed speed plays an important role in WAAM process.
\end{abstract}

Keywords- Wire Arc Additive Manufacturing (WAAM), GTA welding, Taguchi's Method

\section{I- INTRODUCTION}

D ay by day improving Modern industry has three basic requirements Sustainability, Low Cost and environment friendly product which are not satisfied by the conventional manufacturing techniques. Thus, Additive manufacturing become the important industrial process for manufacturing of custom-made products.
Researchers find $\mathrm{AM}$ as a replacement to convention manufacturing method in some industrial applications. $\mathrm{AM}$ has experienced remarkable growth in last few decades, making not only prototypes but able to produce fully functional products. AM technology has been made a significant impact in non-metallic product manufacturing but there is need of research for manufacturing metallic component by means of AM as most of the functional element used in industry like automobile, nuclear and thermal power plant, etc. are of metal. And by using metal AM technique it is possible to manufacture complicated parts in much less time and with minimum wastage of raw material as well as with low cost as compared to conventional manufacturing methods. [1]

Metal additive manufacturing has been in the trend form last decade due to its ability to produce component at reduced cost and low buy-to-fly ratio. There are various techniques employed for metal additive manufacturing depending on energy source and type of raw materials used. Based on raw materials, metal additive manufacturing can be classified as wire-based, powderbased and sheet-based (laminated object manufacturing). Amongst these three, wire-based systems have higher material efficiency and high deposition rates. They also better suited for continuous and uncluttered material supply. Hence, they are most suitable for manufacturing of large components. Wire based systems can be used in 


\section{International Journal of Innovations in Engineering and Science, www.ijies.net}

conjunction with different power sources like laser, electron beam and arc. [2] Among these wire and arc additive manufacturing is a center of attraction now a days due to high deposition rate, low equipment cost, high material utilization and consequent environmental friendliness. WAAM is an integration of arc welding technique with common motion system such as CNC gantry or cartesian robot by means of which the material can be deposited using arc weld technology according to the prescribed path to form a completed product layerby-layer. Integrating robotics and arc welding technique makes WAAM a highly complex system in which many aspects of the process need to be studied, like process development, material quality and performance, path design and programming, process modelling, etc.

This paper manly focuses on the design and development of wire arc-based metal additive manufacturing setup for industrial purpose which include the integration of GTAW technique with specially designed Cartesian robot along with the use of CAD/CAM software for pre-processing, monitoring and control to manufacture a 3D metallic component. As well as the process parameter selection for material ER309L for prescribed WAAM technology has been discussed.

\section{II- LITERATURE REVIEW}

The development of WAAM can be mainly categorized into the three timed sections. Beginning phase started at 1920, second phase of 'building up background' from 1970s until 1990s and the last 'development new era' phase can be extended to date.

In 1920, Baker [3] filed a patent naming 'Method of making decorative articles' which was assigned to the Washington Electric company demonstrated the technique of constructing receptables and decorative articles using non-adherent substrate. He called it as superposed deposit of metal using manipulated helical path of a fusible electrode. The electrode was controlled manually. This formation of receptacles is considered as the foundation stone in the development of WAAM technique.

Wang et al. [4]from Southern Methodist University proposed a WAAM system based on a VP-GTAW heating source for directly building cylindrical parts made of aluminum alloys, such as Al-5356 and Al-4043. The authors emphasized the need for on-line monitoring and control systems of process parameters such as pre- heating, arc-length, heat input, and bead geometry knowledge base for achieving good quality parts.

K.P. Karunakaran, S. Suryakumar [5] have developed hybrid layered manufacturing system using the integration of additive and subtractive manufacturing methods. They have combined the best features of both additive and subtractive approach. Setup that was made named as ArcHLM setup which is integration of weld deposition unit and CNC machine. The interesting inferences were made from this case study: ArcHLM route for this case took $42 \%$ less time than that of the $\mathrm{CNC}$ route. ArcHLM route for this case cost $28 \%$ less than that of the CNC route. Cost of the raw material was lower in ArcHLM for this case study.

Suryakumar [6] studied mechanical properties of objects made through weld deposition for metallic objects made through HLM (hybrid layer manufacturing) to analyze the hardness and tensile strength of WAAM manufactured metallic components. He also tried to conceptualize the effect of thermal cycle on tensile strength and hardness made through hybrid layer manufacturing. Due to thermal variation across layers on increasing $\mathrm{z}$ height difference in maximum hardness he observed on the top layer while it was less in layers below top layers. While for tensile stress it was same for horizontal while in vertical direction it was observed to be lower in vertical direction but it was possible to rectify it by increasing amperage.

Xiong [7] studied the reason behind the poor surface quality in GMAW based AM manufacturing and he tried to study the crucial parameters which affect the surface quality and found interlayer temperature, wire speed and travel speed were important. He found that increasing the interlayer temperature was attributed to increased surface roughness not only that but this even contributed to decreased layer height due to decreased heat conduction rate with increased layer height. He also found that when travel speed (TS) was low that resulted in more height hence caused more stair stepping effect but increasing travel speed was limited to $420 \mathrm{~mm} / \mathrm{min}$ as increasing travel speed beyond it caused poor surface quality due to spatter due to arc instability. While WFS (wire feed speed) when increased caused more surface roughness due to mixing of layers and thus resulted unstable molten pool.

\section{III - METHODOLOGY}

Problem statement- To develop the metal additive manufacturing setup using wire arc additive manufacturing technology. 


\section{International Journal of Innovations in Engineering and Science, www.ijies.net}

The main objectives of this research are as follows -1 . To incorporate weld deposition unit and special purpose robot to form a metal 3D printer. 2. Designing and executing the WAAM process according to the special material used in industry.

Wire + Arc additive manufacturing process is integration of CAD, CAM, direct deposition technology (3D Printing) and welding technology.

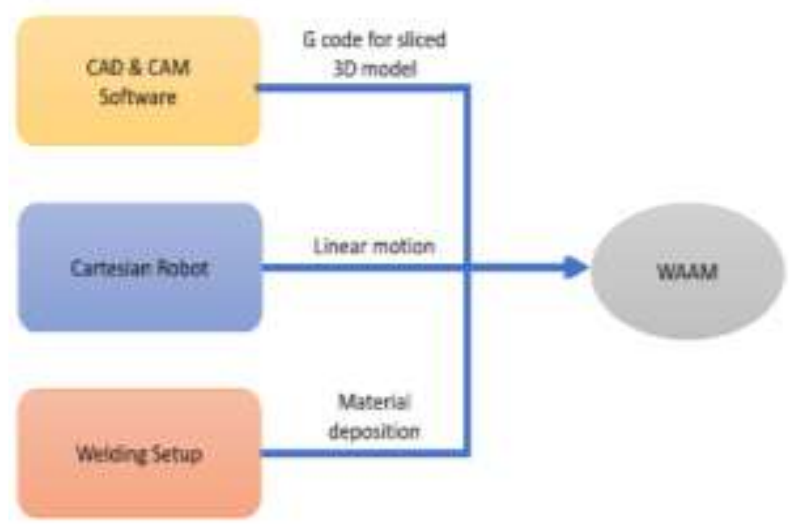

Fig. 1 - Major Components of WAAM

The WAAM setup must be design by combining the principles of all these concepts. The methodology to achieve first objective starts with designing a special purpose cartesian robot including its structural design and selection of essential electronics component which will help to achieve the desired robot motion and execute the metal deposition strategy defined by CAD/CAM software. To execute WAAM on any material, the welding parameterization is important aspect and to finalize optimal parameters the design of experiment has been carried out using Taguchi's method and results are found by $\mathrm{S}-\mathrm{N}$ ratio analysis which achieves the second objective.

\section{IV- DESIGN CONCEPT OF WAAM SETUP}

\section{Cartesian robot}

Robot is the main structural component of whole setup. The most important aspect of any machine is its structural components strength which directly affects the integrity of setup and reliability of machine. In WAAM setup we only require linear motion in three axes i.e. $X$ axis, Y-axis \& Z-axis and that's why cartesian robot is best suited for WAAM application. First step in designing any robot is fixing the Degree of Freedom (DOF) of robot. so, according to the requirement of motion stated before the degree of freedom for Cartesian robot is 3. All these three motions are given to the welding gun nozzle carriage. a workspace of $1 \mathrm{~m}^{*} 1 \mathrm{~m}^{*} 1 \mathrm{~m}$ has been consider. In cartesian method, there will be two horizontal parallel bars at two extreme corners of plane. These bars carry the linear guide rails for smooth linear movement of guide rail block. This archives the $\mathrm{Y}$ axis motion. Connecting the two linear guide blocks, there is one horizontal perpendicular bar is placed. On this a linear guide rail is mounted and on guide rail block the welding torch is mounted. This will achieve $\mathrm{X}$ axis linear motion. So, single bar linear guide rail will provide $\mathrm{X}$-axis motion and supporting two parallel bars will provide $\mathrm{Y}$-axis linear motion. The linear motion has been provided to the linear guide blocks by means of the ball screw mechanism which is driven by motor. According to the load and speed requirement NEMA 17 42HS02 motor has been selected for XY plane motion. The required print volume is $1 \mathrm{~m}^{3}$, so the XY plane mechanism is also of big size, near about $1.3 \mathrm{~m}$ in each side. To support this big structure four ball screws are used at each corner for giving the carriage up \& down motion in Z-axis. NEMA 17 42BYGH4803 motor has been selected for vertical Zaxis motion. Also, for smooth movement and to maintain proper alignment four vertical linear circular guides along with bearing blocks are used.

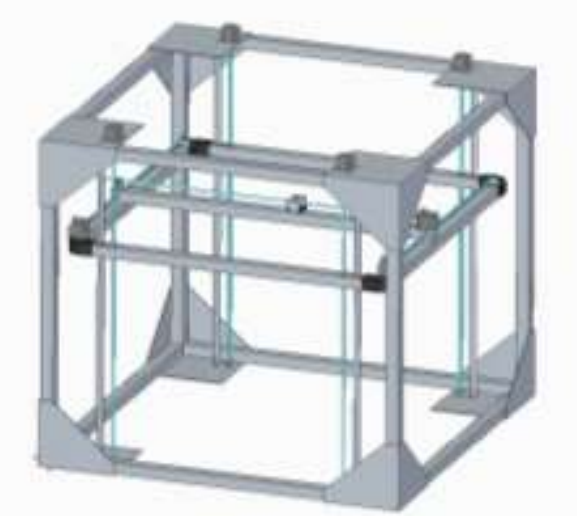

Fig. 2 - 3D CAD Model of Cartesian Robot

\section{Weld deposition unit}

Penetration, productivity and process stability are the important criteria while selecting the welding method and its parameter. The depth to which welding takes place is penetration, for better quality of joint depth must be higher. Productivity is depending on the rate off melt of filler. But when welding is used for continuous weld deposition like in WAAM, higher resolution spatter free operation less heat input becomes the prime criteria. Based on the above inference and considering the 


\section{International Journal of Innovations in Engineering and Science, www.ijies.net}

availability, pulsed GTAW was found to meet the requirement of WAAM. In pulsed TIG mode, the weld heat affected zone is small so the lower heat input and it also consequently reduces the distortion and warpage of workpiece. In addition, it allows greater control of the weld pool with less spatter and can increase weld penetration, welding speed and quality as well. Accordingly, Sigma Weld Alex 400PT welding unit manufactured by Electronics device worldwide Pvt. Ltd. Has been selected for weld deposition. Automatic robotic TIG welding torch has been selected, which can be controlled by means of robot microcontroller. The automatic wire feeder mechanism for TIG must be implemented for continuous deposition. This feeder mechanism is also operated accordingly by the microcontroller.

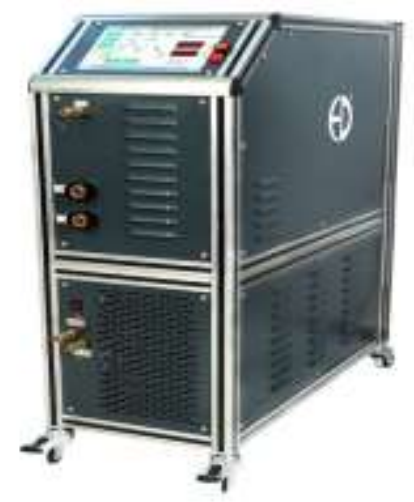

Fig. 3 - Sigma Weld Alex 400PT welding Power source

\section{CAD \& CAM Software}

The most important part in WAAM setup is accurate 3D modelling of part which has to be manufactured by means of layer by layer deposition. Modelling is first step of 3D printing. For 3D modelling a Solid edge software is selected. The 3D modelling software will give the end file format as part file(.prt) containing part structure specifics and 3D model attributes. But this file cannot be directly feed to the WAAM microcontroller. It needs some pre-processing. First this file must be converted into $3 \mathrm{D}$ printable file format i.e. Stereolithography (.stl) or 3D manufacturing Format (.3mf). Once the object part file is converted into 3D printable format, then the slicing of model structure has to be done according to the material properties, printer capabilities, etc. WAAM uses a basic principle of additive manufacturing method to manufacture a product layer by layer, for this purpose the slicing is important. A Slicer is a program that converts digital 3D models into printing instructions for a given $3 \mathrm{D}$ printer to build an object. The working of slicing software is, they take 3D model, make horizontal slices from it, and send the appropriate G-codes to the 3D printer to execute. Ultimaker's Cura is most widely used slicing software which is open source.

\section{Electronic Unit}

The microcontroller board is brain of any automated system. For the application of WAAM, there is a need of microcontroller board with precise control as the operating procedure and control has high constraints. The Printboard AT90USB1286 has been selected for WAAM setup. The major function of microcontroller board is to run the program or G-code event by event, monitors the position of guide blocks of robot as well as position of welding torch and drive the stepper motor through the step sticks. AT90USB1286 has 4 integrated Allegro stepper drive and on board 4 channel DAC which is main reason to select this microcontroller as we need to control four different motors i.e. $\mathrm{X}, \mathrm{Y} \& \mathrm{Z}$ axis motor and one wire feeder motor. A microcontroller is typically programmed with a narrow range of function i.e. to collect the input and produce output. Here microcontroller takes input in form of G-code file produced by slicing software and gives the output is the form motion of cartesian robot carriage and welding torch deposition.

The process flow of WAAM setup is as follows -

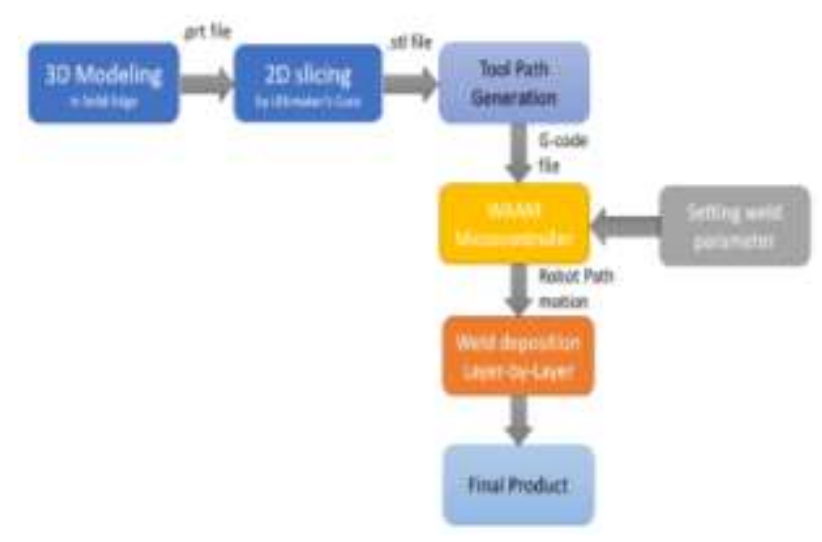

Fig. 4 - The process flow of WAAM

In this way by combining all these i.e. Cartesian Robot, Weld deposition unit, CAD\&CAM software and Electronics unit a WAAM system has been developed.

\section{Welding Parameter selection}




\section{International Journal of Innovations in Engineering and Science, www.ijies.net}

By using available resources, the WAAM test setup has been made. It consists of Cartesian gantry robot, Sigma Weld Alex 400PT TIG welding source, Auto TIG torch, semi-automatic controller, work table. The actual setup is shown in figure ()

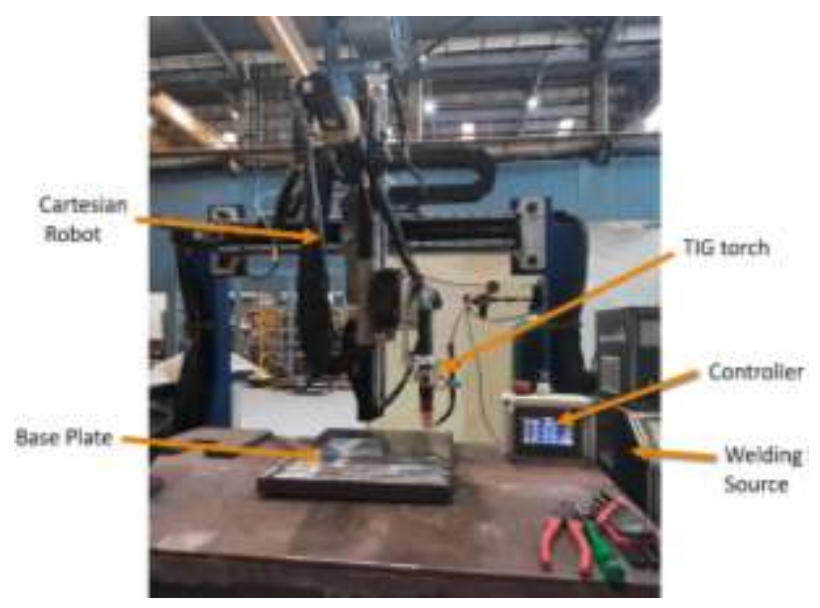

Fig. 5 - WAAM test setup

The metal ER309L has been selected for WAAM application. ER309L is a Pinnacle alloy low carbon steel alloy generally used for welding alloys in wrought and cast form. It has excellent corrosive resistance quality due to nickel and molybdenum. ER309L has Syt 393 MPa; UTS 592 MPA and Elongation of $42 \%$.

Table 1- Chemical composition of ER309L given by manufacturer

\begin{tabular}{|c|c|c|c|c|c|c|c|}
\hline $\mathrm{C}$ & $\mathrm{Ni}$ & $\mathrm{Cr}$ & $\mathrm{Mo}$ & $\mathrm{Si}$ & $\mathrm{Mn}$ & $\mathrm{P}$ & $\mathrm{Fe}$ \\
\hline 0.03 & 13 & 24 & 0.75 & 0.47 & 1.75 & 0.03 & Bal \\
\hline
\end{tabular}

For selection of optimal parameter for ER309L the Design of experiment using Taguchi's Method has been carried out. The welding parameters which affects the weld bead quality are welding current, voltage, wire feed speed, travel speed of weld torch, shielding gas and its flow, feed wire diameter. Out of which the wire diameter is fixed $(1.2 \mathrm{~mm})$. Shielding gas cannot be varied, so it is also fixed. As we are using automatic welding setup, the voltage is depending on current. Arc length is also depending on welding current. So, the independent parameters for WAAM are welding current (I), torch travel speed (TS) and Wire feed speed (WFS). The performance parameters are deposited weld Bead quality, bead width and bead height. For Taguchi's analysis three level of each independent parameter is selected.
Table 2-Process parameters for WAAM deposition

\begin{tabular}{|l|l|l|l|}
\hline Parameter & $\begin{array}{l}\text { Current } \\
\text { (Amp) }\end{array}$ & $\begin{array}{l}\text { Travel } \\
\text { speed } \\
(\mathrm{mm} / \mathrm{min})\end{array}$ & $\begin{array}{l}\text { Wire feed } \\
\text { speed } \\
(\mathrm{mm} / \mathrm{min})\end{array}$ \\
\hline Level 1 & 215 & 130 & 1500 \\
\hline Level 2 & 225 & 140 & 1800 \\
\hline Level 3 & 230 & 150 & 2000 \\
\hline
\end{tabular}

During this experimentation the other parameters setting are, welding electrode - tungsten $(\Phi 3.2 \mathrm{~mm}$ ); shielding gas - 100\% Argon; shielding gas flow - 17-18 LPM; Welding voltage $-15-18$ Volt; welding position is $1 \mathrm{G}$ down-hand.

Table 3-Taguchi's L9 Orthogonal array for welding parameter selection

\begin{tabular}{|l|l|l|l|}
\hline $\begin{array}{l}\text { Trial } \\
\text { No. }\end{array}$ & $\begin{array}{l}\text { I } \\
\mathbf{1} p\end{array}$ & $\begin{array}{l}\text { TS } \\
\mathbf{m m} / \mathbf{m i n}\end{array}$ & $\begin{array}{l}\text { WFS } \\
\mathbf{m m} / \mathbf{m i n}\end{array}$ \\
\hline $\mathbf{2}$ & 215 & 130 & 1500 \\
\hline $\mathbf{3}$ & 215 & 140 & 1800 \\
\hline $\mathbf{4}$ & 215 & 150 & 2000 \\
\hline $\mathbf{5}$ & 225 & 130 & 1800 \\
\hline $\mathbf{6}$ & 225 & 140 & 2000 \\
\hline $\mathbf{7}$ & 230 & 150 & 1500 \\
\hline $\mathbf{8}$ & 230 & 140 & 2000 \\
\hline $\mathbf{9}$ & 230 & 150 & 1800 \\
\hline & & & 1500 \\
\hline
\end{tabular}

\section{V- RESULT \& DISCUSSION}

According to the Taguchi's orthogonal array, the 9 trials has been conducted for ER309L material in WAAM setup. The resultant bead structure and parameters has been recorded. The bead width and bead height has been measured by using digital vernier caliper and height gauge and the bead quality has been identified by the visual inspection.

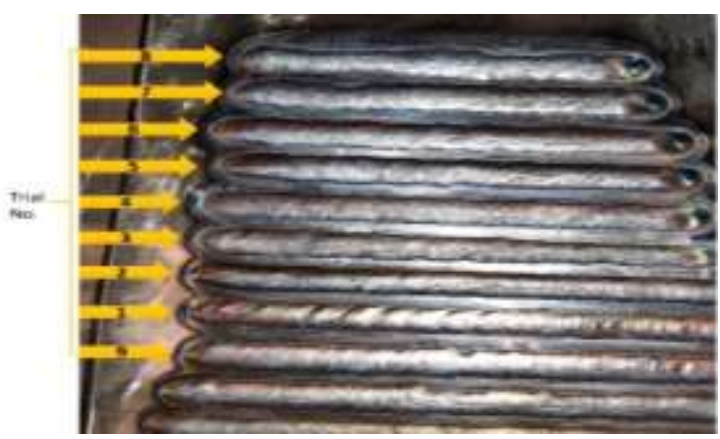

Fig. 6- L9 trials bead profiles according to Taguchi's $O A$ 


\section{International Journal of Innovations in Engineering and Science, www.ijies.net}

For determining the optimal parameter signal-to-noise ratio analysis has been caried out using the Minitab 19 software. Nominal is best criteria is used while calculating the $\mathrm{S} / \mathrm{N}$ ratio as we required nominal optimal value of resultant parameters. The resultant parameter measure value and respective $\mathrm{S} / \mathrm{N}$ ratio value for respective trial is mentioned in table no. 4

Table 4- Resultant parameter value and S/N ratio

\begin{tabular}{|c|c|c|c|c|}
\hline \multirow{2}{*}{$\begin{array}{l}\text { Trial } \\
\text { no. }\end{array}$} & \multicolumn{3}{|c|}{ Resultant Parameters } & \multirow[b]{2}{*}{$\mathrm{S} / \mathrm{N}$ ratio } \\
\hline & $\begin{array}{l}\text { Bead } \\
\text { Width }\end{array}$ & $\begin{array}{l}\text { Bead } \\
\text { Height }\end{array}$ & $\begin{array}{l}\text { Bead } \\
\text { Quality }\end{array}$ & \\
\hline 1 & 11.5 & 1.0 & $\mathrm{Bad}$ & -6.8065 \\
\hline 2 & 11.0 & 1.3 & Good & -5.1717 \\
\hline 3 & 10.0 & 1.2 & $\mathrm{Bad}$ & -5.0875 \\
\hline 4 & 12.3 & 1.6 & Good & -4.6371 \\
\hline 5 & 12.5 & 1.5 & $\mathrm{Bad}$ & -5.0875 \\
\hline 6 & 11.5 & 1.2 & $\mathrm{Bad}$ & -5.8476 \\
\hline 7 & 12.0 & 1.5 & Good & -4.8607 \\
\hline 8 & 9.5 & 1.2 & $\mathrm{Bad}$ & -4.8022 \\
\hline 9 & 11.0 & 1.3 & Good & -5.1717 \\
\hline
\end{tabular}

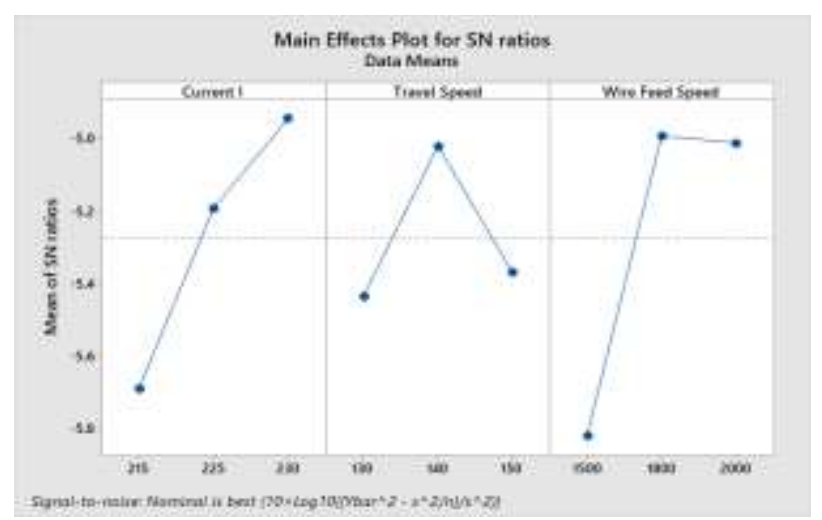

Fig. 7 - Main effect plot for SN ratio

1. The plot for $\mathrm{S} / \mathrm{N}$ ratio indicates that the $\mathrm{S} / \mathrm{N}$ ratio increases rapidly when current changes from $215 \mathrm{~A}$ to $225 \mathrm{~A}$. But when current goes from $225 \mathrm{~A}$ to 230 $A$ the $\mathrm{S} / \mathrm{N}$ ratio increases linearly. That means the optimal value is $225 \mathrm{Amp}$.

2. The $\mathrm{S} / \mathrm{N}$ ratio increases linearly when travel speed changes from $130 \mathrm{~mm} / \mathrm{min}$ to $140 \mathrm{~mm} / \mathrm{min}$ and when it further changes to $150 \mathrm{~mm} / \mathrm{min}$ the $\mathrm{S} / \mathrm{N}$ ratio decreases linearly. So, the nominal value is 130 $\mathrm{mm} / \mathrm{min}$

3. Main effect plot shows that when WFS changes from 1500 to $1800 \mathrm{~mm} / \mathrm{min} \mathrm{S} / \mathrm{N}$ ratio changes drastically. But when WFS changes from 1800 to
$2000 \mathrm{~mm} / \mathrm{min}$ the value for $\mathrm{S} / \mathrm{N}$ ratio is nearly constant. So, the $1800 \mathrm{~mm} / \mathrm{min}$ is the nominal value.

Table 5 - Response Table for Signal to Noise Ratios

\begin{tabular}{|l|l|l|l|}
\hline Level & Current & $\begin{array}{l}\text { Travel } \\
\text { Speed }\end{array}$ & $\begin{array}{l}\text { Wire } \\
\text { Speed }\end{array}$ \\
\hline 1 & -5.689 & -5.435 & -5.819 \\
\hline 2 & -5.191 & -5.021 & -4.994 \\
\hline 3 & -4.945 & -5.369 & -5.012 \\
\hline Delta & 0.744 & 0.414 & 0.825 \\
\hline Rank & 2 & 3 & 1 \\
\hline
\end{tabular}

In response table the factors have been ranked on the basis of absolute difference in level of $\mathrm{S} / \mathrm{N}$ ratio between max and min value of each factor. The relative ranking of input parameters influencing the bead quality was obtained by analysis of $\mathrm{S} / \mathrm{N}$ data. Wire feed speed has highest delta value that's why 1 rank has been given to it which states that the wire feed speed is most significant parameter followed by current.

The optimal welding parameter values foe WAAM process are shown in table 6.

Table 6 - optimal value of welding parameters for WAAM

\begin{tabular}{|l|l|l|l|}
\hline $\begin{array}{l}\text { Input } \\
\text { parameter }\end{array}$ & $\begin{array}{l}\text { Current } \\
\text { (I) }\end{array}$ & $\begin{array}{l}\text { Travel speed } \\
\text { (TS) }\end{array}$ & $\begin{array}{l}\text { Wire Feed } \\
\text { Speed } \\
\text { (WFS) }\end{array}$ \\
\hline $\begin{array}{l}\text { Optimal } \\
\text { value }\end{array}$ & $225 \mathrm{Amp}$ & $130 \mathrm{~mm} / \mathrm{min}$ & $\begin{array}{l}1800 \\
\mathrm{~mm} / \mathrm{min}\end{array}$ \\
\hline
\end{tabular}

\section{VI- CONCLUSION}

In this study, the detail design of WAAM setup has been discussed and demonstrated. As well the Analysis of S/N ratio for selection of optimal welding parameter for WAAM application has been discussed. The following conclusions drawn from the study:

1. WAAM is the best suited manufacturing method for Metallic components due to its high deposition rate, large build volume, high buy-to-fly ratio and relatively low feedstock cost as well as substantial reduction in material waste and less time is also possible due to WAAM.

2. The wire arc additive manufacturing setup has been designed by combining the principles robotics, welding technology and CAD/CAM technique. 
Vol. 6, No. 10, 2021, PP. 80 -86

\section{International Journal of Innovations in Engineering and Science, www.ijies.net}

3. It has been found that the wire feed speed plays an important role for the weld deposition in WAAM application.

4. Taguchi's optimization and $\mathrm{S} / \mathrm{N}$ data revels that the optimal welding parameter for EN309L material are 225 Amp current, $130 \mathrm{~mm} / \mathrm{min}$ travel speed and $1800 \mathrm{~mm} / \mathrm{min}$ wire feed speed.

\section{REFERENCES}

[1] S. W. Williams, F. Martina, A. C. Addison, "Wire + Arc Additive Manufacturing," Materials Science and Technology, vol. 32, no. 7, pp. 641-647, 2016.

[2] Bintao Wua, Zengxi Pana, Donghong Dingb, Dominic Cuiuria, Huijun Lia, Jing Xuc, John Norrisha, "A review of the wire arc additive manufacturing of metals: properties, defects and quality improvement," Journal of Manufacturing Processes, vol. 35, pp. 127-139, 2018.

[3] R. Baker, "Method of Making Decorative Articals". US Patent 1533300, 14 April 1925.

[4] Huijun Wang, Wenhui Jiang, "Rapid Prototyping of 4043 Al-alloy part by VP-GTAW," Journal of Materials Processing Technology, vol. 148, pp. 93-102, 2004.

[5] K.P. Karunakaran, S.Suryakumar, VishalPushpa, SreenathbabuAkula, "Low cost integration of additive and subtractive processes for hybrid Layer Manufacturing," Robotics and Computer-Integrated Manufacturing, vol. 26, pp. 490 - 499, 2010.

[6] Simhambhatla Suryakumar, KP Karunakaran, $U$ Chandrasekhar, MA Somashekara, "study of the mechanical properties of objects built through welddeposition," Proceedings of the Institution of Mechanical Engineering, vol. 227, no. 8, pp. 1138-1147, 2013.

[7] Jun Xiong, Yanjiang Li, Rong Li, and Ziqiu Yin, "Influences of process parameters on surface roughroughness of multi-layer single-pass thin-walled parts in gmaw-based additive manufacturing.," Journal of Materials Processing Technology, vol. 252, pp. 128-136, 2018. 